\title{
A Novel Method for Synthesis of Chiral Polymer Useful for Membrane Application
}

\author{
By Swapnali HAZARIKA, ${ }^{*}$ Somiron BorthaKUR, Paruchuri G. RAO, and Narendra N. DUTTA
}

A Chiral polymer from 1,2-bis(2-methyl-1-triethylsiloxy-1-propenyloxy)ethane and dialdehyde from adipoyl chloride and 4hydroxy benzaldehyde has been prepared in gram scale level and characterized by IR, NMR, TGA, DSC, optical rotation and Circular dichrosm (CD) study. The same was used for preparation of enantioselective membrane by phase inversion technique and the membrane was characterized for pore size and surface morphology through SEM (Scanning Electron Microscope) analysis. The enantioselective property of the membrane in the resolution of racemic compounds was studied using aqueous solution of Atenolol, Captopril, Propranolol hydrochloride and Salbutamol as feed solution. Pressure driven membrane processes were studied under pressure $4.84 \times 10^{-2} \mathrm{~N} / \mathrm{m}^{2}, 24.22 \times 10^{-2} \mathrm{~N} / \mathrm{m}^{2}$ and $48.44 \times 10^{-2} \mathrm{~N} / \mathrm{m}^{2}$. The Effect of feed concentration and operating pressure on membrane performance were studied differently. Solution diffusion model have been used to explain the permeation behaviour of the membrane. From this type of membrane $95 \%$ ee and $6.4 \mathrm{mg} / \mathrm{m}^{2} \mathrm{~h}$ of flux were obtained.

KEY WORDS: Atenolol / Captopril / Propranolol Hydrochloride / Salbutamol / Enantioselective Membrane /

Chiral polymers are important in various applications, including the separation of racemic compounds and polymeric catalysis in asymmetric synthesis. ${ }^{1}$ Although various methods have been developed to synthesize chiral polymers, we focus on repetitive asymmetric reaction between prochiral monomers using a chiral catalyst. Asymmetric polymerization by means of repetitive asymmetric $\mathrm{C}-\mathrm{C}$ bond forming reactions in the presence of a chiral catalyst gives optically active polymers having main chain configurational chirality. Novel optically active polymers have been prepared by asymmetric polymerization methods based on asymmetric reactions, such as asymmetric Diels-Alder reaction, asymmetric addition of allylsilane to aldehyde and asymmetric Mukaiyama aldol reaction. ${ }^{1}$ These asymmetric reactions are used for chiral polymer synthesis by repetitive asymmetric reaction between prochiral monomers to give optically active polymers. Recent progress in the method of asymmetric synthesis prompted us to design new chiral polymers by repetitive asymmetric reaction. This type of polymerization is attracting attention as one of the efficient methods for accessing optically active polymers.

The Mukaiyama aldol reaction is an important $\mathrm{C}-\mathrm{C}$ bond forming reaction. Based on this reaction, a number of complicated molecules, including naturally occurring compounds have been skillfully synthesized. In polymer synthesis, this type of reaction has been used as a new polymerization method called 'aldol group transfer polymerization' (aldolGTP). All of the dialdehyde monomer used in asymmetric polymerization are useful for the aldol polymerization. Various catalytic asymmetric Mukaiyama aldol reactions of silyl enol ethers and aldehydes have been studied using chiral catalyst. ${ }^{1}$ Due to remarkable ability of triethylsilyl group to stabilize silyl ethers, and to obtain higher enantioselectivity, triethylsilyl enol ether is mostly used in Mukaiyama aldol reactions. ${ }^{2}$ We have been synthesized chiral polymers from 1,2-bis(2-methyl-1triethylsiloxy-1-propenyloxy)ethane and dialdehyde produced from Succinoyl chloride and 4-hydroxybenzaldehyde. The polymer produced is used for enantioselective separation of trans sobrerol. ${ }^{3}$

Optically active compounds show varied bioactivities and one enantiomer of the same compound may have adverse effect in the human body. So, to be safe and effective they should be used in optically pure form in medicine and agricultural chemicals. Therefore, optical resolution of enantiomers has significant importance in view of getting optically pure compound. Optical resolution through solid membrane is expected to realize the treatment of a large amount of racemic compounds. Several optical resolutions by solid membranes have been reported. ${ }^{3-12}$ But they had several disadvantages, for example low selectivity, low permeability, and/or low mechanical strength. However, a few membranes showed enantioselective permeability with high enantioselectivity for various racemates and some other membranes has low permeation rate and they are not able to separate hydrophobic racemates because the polymer membranes were swelled by hydrophobic racemates. ${ }^{411}$ Thus there is need for developing enantioselective membrane with high permeability and high selectivity.

In this study, we synthesized an optically active polymer poly ( $\beta$-hydroxy carbonyls) by aldol polymerization based on Mukaiyama Aldol reaction using lipase as the catalyst. This polymer has been used for preparation of enantioselective membrane for resolution of Atenolol, Captopril, Salbutamol and Propranolol hydrochloride. A quantitative structure activity relationship study has also been made between permeation flux and molecular properties of the permeates. 


\section{EXPERIMENTAL}

\section{Materials and Methods}

Lipase from Candida rugosa, Atenolol, Captopril, Salbutamol, Propranolol hydrochloride and polysulfone (average mol. Wt. 30,000) were supplied by Aldrich Chemical Company, USA, $N$-methyl pyrrolidone (NMP) was supplied by SRL-India. Triethylsilane, Ethylene glycol dimethacrylate (EGDA), Adipoyl chloride, 4-hydroxybenzaldehyde, Sodium hydride and the solvents were procured from Ranbaxy Fine Chemical Ltd. New Delhi, India.

\section{Analytical Methods}

Infra Red (IR) spectras were obtained on Perkin Elmer, System 2000 FT/IR Infrared spectrophotometer. Data for ${ }^{1} \mathrm{H}$ NMR and ${ }^{13} \mathrm{C}$ NMR spectras were recorded using BRUKER ADVANCE DPX-300 MHz spectrometer. Chemical shifts were reported in ppm down field from tetramethylsilane with solvent resonance as the internal standard. Optical rotations were determined by JASCO Digital Polarimeter P1020 using chloroform as the solvent. Circular dichroism study was done by JASCO J810C instrument using chloroform as the solvent at a speed $20 \mathrm{~nm} / \mathrm{min}$ and wavelength range 240$550 \mathrm{~nm}$. The cell path length was $1 \mathrm{~cm}$ with a bandwidth $1 \mathrm{~nm}$ at a temperature $20^{\circ} \mathrm{C}$.

Molecular weight of the polymer was determined by measuring percentage of Silicon in the polymer assuming that copolymer formed in the polymerization reaction was of the type $(A B)_{n}$. Percentage of Silicon in the polymer was measured by X-ray Flourescence analysis (XRF) on a SPECTRO XEPOS Benchtop XRF Spectrometer (version 1.0). For XRF analysis the samples were prepared by mixing polymer with wax with a ratio of 4:1 and then homogenized it. By applying pressure on the homogenized mixture a pallet has been prepared and analyzed by XRF which gives the percentage of silicon in the polymer sample. Molecular weight of the polymer was found to be 74500 .

Thermogravimetry (TG) and differential thermogravimetry (DTG) were performed using a Shimadzu Thermal Analyzer 30 at a heating rate of $10^{\circ} \mathrm{C} / \mathrm{min}$ using $5 \pm 1 \mathrm{mg}$ of powdered samples in the temperature range from $30^{\circ} \mathrm{C}$ to $500^{\circ} \mathrm{C}$. Differential scanning calorimetry (DSC) was performed on a Perkin Elmer PC series DSC 7 with $3-5 \mathrm{mg}$ of polymer samples weighed in aluminium pans at a heating rate of $10^{\circ} \mathrm{C} /$ min. All experiments were carried out in nitrogen atmosphere and the measurement was started as soon as the heat flow in the DSC cell had stabilized.

The HPLC measurements were carried out on a Waters modular system consisting of two 510 pumps, an automated gradient controller, U6 K injector and a 486 tunable absorbance detector. The chiral column required for resolution of racemic compound with eluents are given in Table I. All chiral columns were purchased from DAICEL CHEMICAL INDUSTRIES Ltd. The samples were detected with UV $210 \mathrm{~nm}$ and flow rate of $1 \mathrm{~mL} / \mathrm{min}$.
Table I. Chiral column with eluents required for resolution of racemic compound

\begin{tabular}{|c|c|c|}
\hline $\begin{array}{l}\text { Racemic } \\
\text { compound }\end{array}$ & $\begin{array}{l}\text { Chiral } \\
\text { column }\end{array}$ & Eluents \\
\hline Propranolol & OD-R & $0.1 \mathrm{MKPF}_{6}$ aq. $(\mathrm{pH} 6) / \mathrm{CH}_{3} \mathrm{CN}$ \\
\hline Hydrochloride & & $(60 / 40)$ \\
\hline Atenolol & OD-R & $\begin{array}{c}0.1 \mathrm{MKPF}_{6} \text { aq. }(\mathrm{pH} 6) / \mathrm{CH}_{3} \mathrm{CN} \\
(80 / 20)\end{array}$ \\
\hline Salbutamol & OD & $\begin{array}{c}n \text {-hexane/2-propanol/diethylamine } \\
\qquad(80 / 20 / 0.1)\end{array}$ \\
\hline Captopril & OD-R & $\begin{array}{c}1 \mathrm{M} \mathrm{NaClO}_{4} \text { aq./CH3CN/MeOH } \\
(40 / 15 / 45)\end{array}$ \\
\hline
\end{tabular}

\section{Synthesis of Monomer}

Monomer 1. To a stirred suspension of $\mathrm{NaH}(0.2 \mathrm{gm} .8 .33$ $\mathrm{mmol})$ in anhydrous THF, $1.02 \mathrm{gm}(8.33 \mathrm{mmol})$ of 4-hydroxybenzaldehyde was added under $\mathrm{N}_{2}$ atmosphere, and the mixture was stirred at $0{ }^{\circ} \mathrm{C}$ for $1 \mathrm{~h}$. Then $2.7 \mathrm{~mL}$ ( $\left.24.5 \mathrm{mmol}\right)$ of Adipoyl chloride was added and the reaction mixture was stirred for $20 \mathrm{~h}$. at room temperature. Then water was slowly added into the resulting mixture. After the reaction was completed, the aqueous layer from organic layer was separated by using separating funnel. After the organic layer was separated, the residual aqueous layer was extracted twice with ethyl acetate. The combined organic layer was dried over $\mathrm{Na}_{2} \mathrm{SO}_{4}$. The mixture was then filtered and concentrated in a rota vapour to give the solid product and recrystallized the crude product from hexane/EtOAc (yield 22.45\%). ${ }^{1} \mathrm{H}$ NMR ( $\delta$ in ppm from TMS in $\mathrm{CDCl}_{3}$ ): 1.90(br s, 4H), 2.67 (br s, 4H), $7.28(\mathrm{~d}, 4 \mathrm{H}), 7.93(\mathrm{~d}$, $4 \mathrm{H}), 10.00(\mathrm{~s}, 2 \mathrm{H}){ }^{13} \mathrm{C}$ NMR: 24.06, 33.89, 122.26, 131.16, 134.02, 155.29, 170.91, 190.78, mp 97-98; $\operatorname{IR}\left(\mathrm{KBr}, \mathrm{cm}^{-1}\right)$ 2951, 2857, 1756, 1698, 1596, 1374, 1261, 1153, 1008, 922, $857,508$.

Monomer 2 (1,2-Bis(2-methyl-1-triethylsiloxy-1-propenyloxy)ethane). This monomer is prepared by the method reported in our previous study. ${ }^{3}$

\section{Synthesis of Chiral Polymer}

Lipase Catalyzed Polymerization Reaction. $30 \mathrm{mg} / \mathrm{mL}$ of Candida rugosa lipase was mixed with toluene at room temperature. After stirring for $30 \mathrm{~min}$. the solvent was removed and the resulting white solid was suspended in $20 \mathrm{~mL}$ dichloromethane. Then a $\mathrm{CH}_{2} \mathrm{Cl}_{2}$ solution of $0.802 \mathrm{mmol} / \mathrm{L}$ of monomer 1 and $0.726 \mathrm{mmol} / \mathrm{L}$ of monomer 2 were added successively to the catalyst solution. The resulting mixture was stirred for $70 \mathrm{~h}$ at $30^{\circ} \mathrm{C}$. After removal of the solvent, the solid product is mixed with THF solution and then the THF solution of the crude product was poured into $\mathrm{MeOH} / \mathrm{H}_{2} \mathrm{O}(2: 1)$. The precipitated polymer was filtered and dried in vacuo (Yield $38 \%)$.

\section{Preparation of Membrane}

The membranes were cast from a solution consisting of polysulphone, chiral polymer, polyethylene glycol (as additive) and $\mathrm{LiNO}_{3}$ (as the swelling gel) in NMP as solvent. The weight ratio of the components were given in Table II. All the 
Table II. Physical properties of chiral membrane, Wt. of polysulfone $=15 \%$, Wt. of additive $=1 \%$, Wt of $\mathrm{LINO}_{3}=0.1 \%$, Solvent- $N$-methyl pyrrolidone

\begin{tabular}{ccccc}
\hline $\begin{array}{c}\text { Wt \% of } \\
\text { chiral } \\
\text { polymer }\end{array}$ & $\begin{array}{c}\text { Membrane } \\
\text { thickness } \\
(\mu \mathrm{m})\end{array}$ & $\begin{array}{c}\text { Pore } \\
\text { diameter } \\
(\mu \mathrm{m})\end{array}$ & $\begin{array}{c}\text { Surface } \\
\text { porosity } \\
(\varepsilon \%)\end{array}$ & $\begin{array}{c}\text { Pure water } \\
\text { permeability } \\
\left(\mathrm{g} . \mathrm{m} \mathrm{m}^{-2} \mathrm{~h}^{-1}\right)\end{array}$ \\
\hline 7.5 & 131 & 0.05 & 2.23 & $5.09 \times 10^{-6}$ \\
8.5 & 14 & 0.01 & 0.30 & $6.99 \times 10^{-6}$ \\
9.5 & 75 & 0.21 & 0.22 & $3.11 \times 10^{-6}$
\end{tabular}

components were stirred at $45^{\circ} \mathrm{C}$ until a homogeneous solution was achieved. Films were casted on a glass plate with Doctor's knife by the common phase inversion process. The solvent from the membrane was evaporated in an oven at $80^{\circ} \mathrm{C}$ for 2-3 h and gelation was done in ice-cold water for $24 \mathrm{~h}$.

\section{Characterization of Membrane}

The enantioselective membrane was characterized by membrane surface morphology, pore size and flux of pure water permeation. Membrane surface morphology was studied by Scanning electron microscope (LEO 1430VP, UK), which directly provides the visual information of the membrane morphology such as pore shape, size, their distribution and density. Computerized analysis of SEM image is a standard and widely used method for the investigation of perforated materials. ${ }^{3}$ In the present study, Image J Launcher Broken Symmetry Software is used to measure the morphological parameters such as pore size and the pore size distribution of each membrane. For this, SEM photographs are taken at different locations of the same membrane sheet from which the pore sizes are measured. This gives us the information regarding the number of pores of different pore size ranges from which percentage of pores of various pore size ranges can be calculated. Plotting percentage of numbers of pores against pore size gives the pore size distribution curve. In this study, average (or mean) pore radius is considered as a substitution for the true pore radius. The mean pore radius, surface porosity, pore density and pore size of the membrane was calculated by the procedure reported in our previous communication. ${ }^{3}$

The thickness of the prepared membrane was calculated from SEM photographs of the cross-section of the membranes using standard technique reported in literature. ${ }^{13}$ Such photographs also provide us with the information regarding the structure and the presence of any micro voids in the sub layer of the membrane sheets. Some SEM photographs of chiral membranes are shown in Figure 1.

Pure water permeability was measured in a membrane cell of standard design fabricated by our group. The membranes with effective area of $28.3 \mathrm{~cm}^{2}$ were set in the test cell and the pure water permeability test was carried out by applying $3.94 \times 10^{-2} \mathrm{~N} / \mathrm{m}^{2}$ pressure to the feed side. The quantity of water permeated through the membrane was measured as permeation rate $\left(\mathrm{g} \mathrm{m} \mathrm{m}^{-2} \mathrm{~h}^{-1}\right)$. Some physical properties of chiral membrane such as membrane thickness, pore diameter, surface porosity and pure water permeability of chiral membranes are shown in Table II.

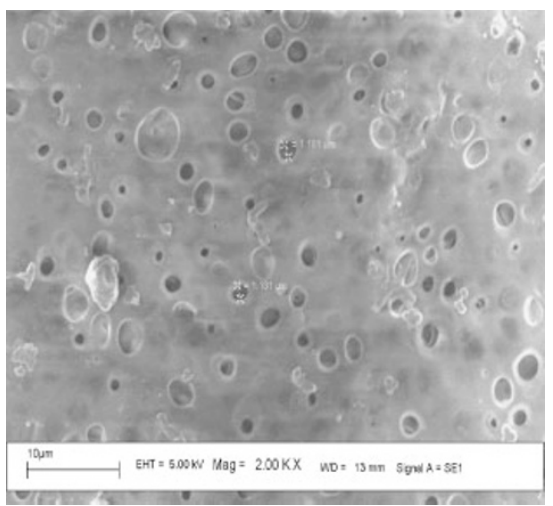

(a)

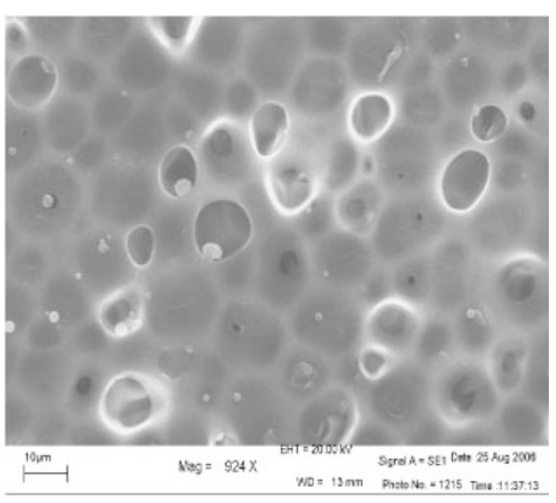

(b)

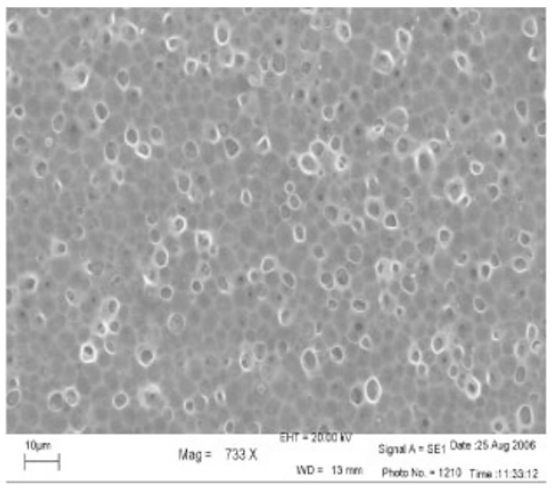

(c)

Figure 1. SEM photograph of chiral membrane.

\section{Adsorption Experiment}

For adsorption experiment, $20 \mathrm{~mL}$ of aqueous solution of racemic compound was contacted with pre-weighed chiral membrane containing different amount of chiral polymer between $0.05 \mathrm{~g}$ to $0.2 \mathrm{~g}$ and was placed in a thermo stated shaker maintained at $25 \pm 0.5^{\circ} \mathrm{C}$. Preliminary run showed that adsorption equilibrium was achieved after $6 \mathrm{~h}$ of contact time for aqueous solution of racemic compounds and accordingly, all equilibrium experiments were conducted at $7-8 \mathrm{~h}$. The initial concentrations of racemic compounds were taken between $2 \mathrm{mM}$ to $8 \mathrm{mM}$. The samples were collected at a 


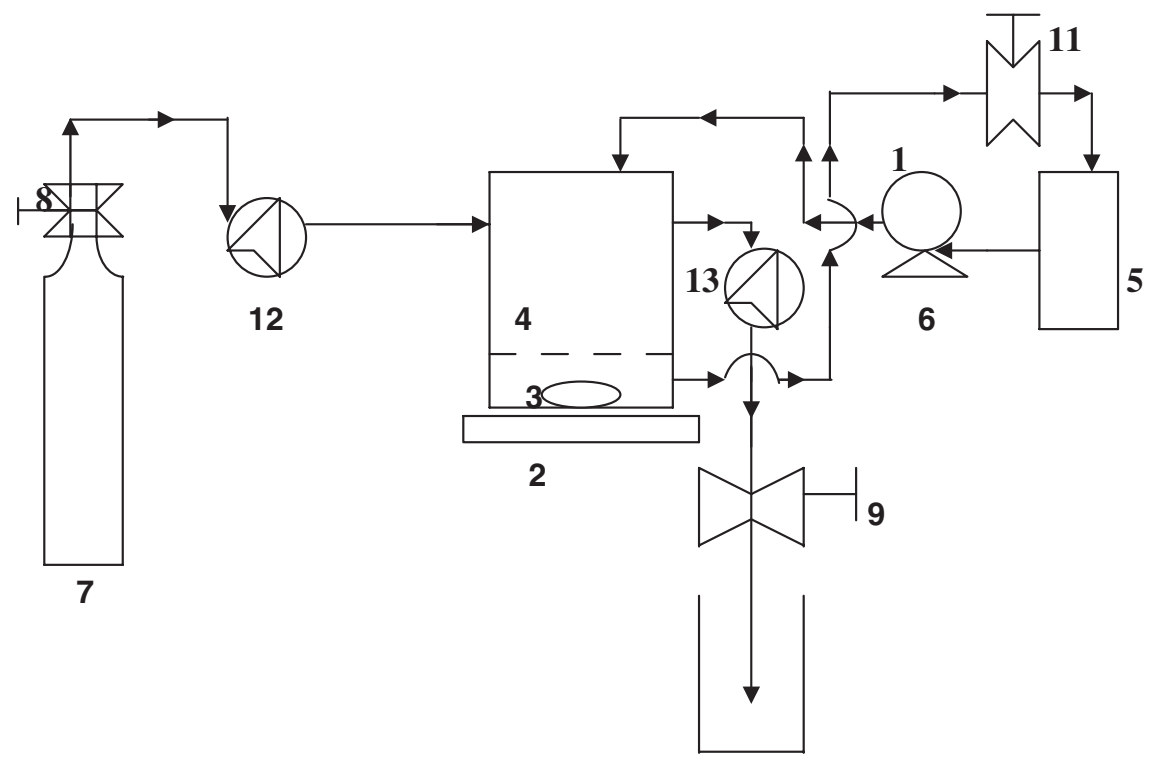

10

Figure 2. Flow diagram of permeation experiment.

1. Membrane cell 2. Magnetic stirrer 3. Magnetic capsule 4. Membrane 5. Feed tank 6. Peristaltic pump 7. $\mathrm{N}_{2}$ gas 8. Gas valve 9 . Gas valve 10. Water vessel 11. Sample collecting valve 12. Pressure gauze 13. Pressure gauze

regular interval of time till the equilibrium is achieved and analyzed by HPLC chiral column. The amount of R- or Sisomer adsorbed per gm of chiral polymer $q\left(\mathrm{mmol} \mathrm{g}^{-1}\right)$ was calculated as $q=V_{1} \Delta C / W_{1}$. where, $\Delta C$ is the change in solute concentration (mM) $V_{1}$ is the solution volume (L) and $W_{1}$ is the weight of adsorbent ( $\mathrm{g}$ ).

\section{Permeation Experiment}

A disproportionate two-compartment membrane cell (Figure 2) whose compartment volumes on the feed side and permeate side were 150 and $20 \mathrm{~mL}$ respectively was used. The polymeric membrane was placed between the compartment with silicone-rubber packing and the cell was connected with a reservoir of $500 \mathrm{~mL}$. Aqueous solution of the racemic compounds was used as the feed solution. The concentration of the feed solutions were $2 \mathrm{mM}, 4 \mathrm{Mm}, 6 \mathrm{mM}$ and $8 \mathrm{mM}$. The operating pressures were $4.84 \times 10^{-2} \mathrm{~N} / \mathrm{m}^{2}, 24.22 \times 10^{-2}$ $\mathrm{N} / \mathrm{m}^{2}$ and $48.44 \times 10^{-2} \mathrm{~N} / \mathrm{m}^{2}$ and the operating temperature was $25^{\circ} \mathrm{C}$. The aqueous solution of different racemates were stirred continuously and circulated by peristaltic pump that was connected to the reservoir. The area of the membrane was $28.3 \mathrm{~cm}^{2}$ and the trans membrane pressure of the experiment was $0.95 \mathrm{~N} / \mathrm{m}^{2}$. Flux for various racemic compounds $(\mathrm{g} \mathrm{m} /$ $\mathrm{m}^{2} \mathrm{~h}$ ) were determined from the concentration of the permeate solution and its volume, using the molecular weight of permeate, i.e.,

$$
\text { Flux, } \mathrm{J}=\mathrm{Q} / \mathrm{A} t
$$

Where $\mathrm{Q}$ is the quantity of the solute permeated for a given time, $t$, the permeation time and $\mathrm{A}$ is the membrane area. The compositions (contents of the $\mathrm{R}$ and $\mathrm{S}$-isomers) of the feed and permeates were measured by HPLC chiral column. The enantiomeric excess (ee) of permeates were determined from the areas of their two enantiomers R-isomer $\left(\mathrm{A}_{\mathrm{R}}\right)$ and $\mathrm{S}$-isomer $\left(\mathrm{A}_{\mathrm{S}}\right)$.

$$
\text { ee }(\%)=100 \times \frac{A_{R}-A_{S}}{A_{R}+A_{S}}
$$

\section{RESULTS AND DISCUSSION}

\section{Characterization of Chiral Polymer}

The chiral polymer was synthesized from the co polymerization of 1,2-bis(2-methyl-1-triethylsiloxy-1-propenyloxy)ethane and dialdehyde prepared from adipoyl chloride and 4hydroxybenzaldehyde using lipase as the catalyst (Scheme 1). This polymer showed the best membrane forming ability as the polymer showed large values of molar elipticity in the UV region. ${ }^{13}$ It is worth noting that, in spite of a very bulky substituent, a high molecular weight polymer capable of forming a tough membrane could be obtained. ${ }^{14}$ The optical rotation $\left([\alpha]^{25}, \mathrm{c}=1\right.$ in $\left.\mathrm{CHCl}_{3}\right)$ values of the chiral polymer was +9.8 . From the optical rotation value, the existence of secondary structure cannot be inferred in case of co-polymer, but the same can be obtained using circular dichrosm (CD) measurement. Figure 3 shows the circular dichrosm spectra of the chiral polymer. The spectrum shows a negative cotton effect at $250 \mathrm{~nm}$ and a positive one at $235 \mathrm{~nm}$, respectively. The polymer showed large values of the molar elipticity ${ }^{3}$ in the UV region, is assigned to adsorption by the main chain, and come to the conclusion that the polymer has one handed helical main chain, similar to the results as reported by Teraguchi et al. ${ }^{15}$ 
<smiles>CCOC(OCCOC(OCC)=C(C)C)=C(C)C</smiles><smiles>CCOC(C(=O)OCCOC(=O)C(C)(C)C(C)(C)CC)c1ccc(OC(C)=O)cc1</smiles>

Scheme 1.

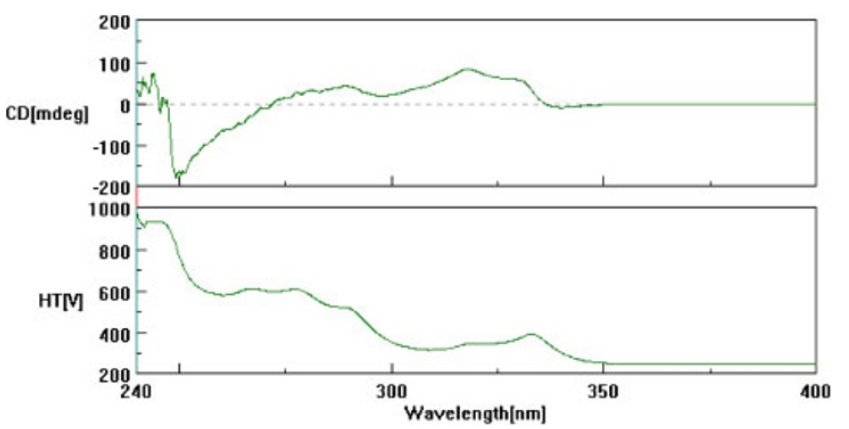

Figure 3. CD spectra of chiral polymer.

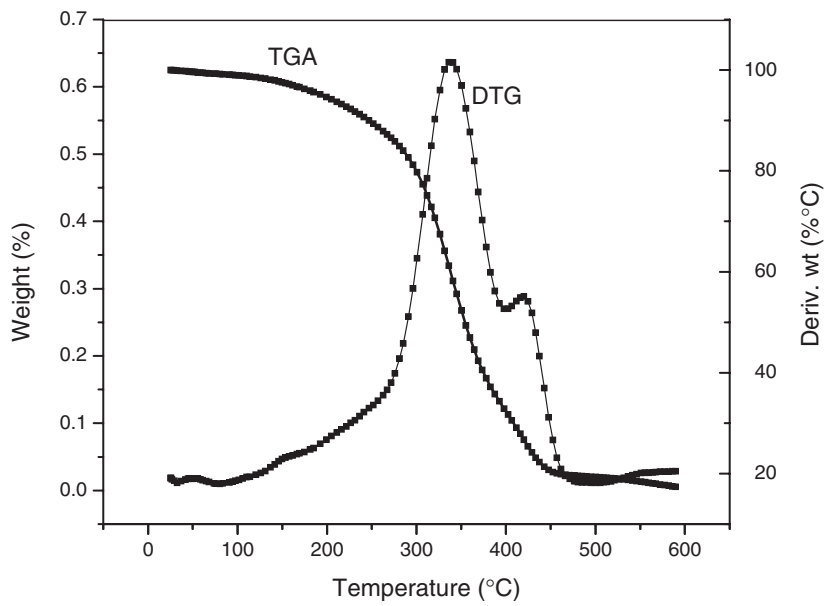

Figure 4. Thermogravimetric and Differential thermogravimetric curve of chiral polymer.

The decomposition curve of the chiral polymer is shown in Figure 4 wherein the derivative curve is also shown. From the results of TGA study on the chiral polymer under nitrogen support one-step decomposition is apparent and decomposition starts above $240^{\circ} \mathrm{C}$. As the decomposition temperature is high enough, it can tolerate the applied thermal stress during the usage. When the chiral polymer degrades, it leaves nearly no residue at and above $460^{\circ} \mathrm{C}$. DSC measurements of the

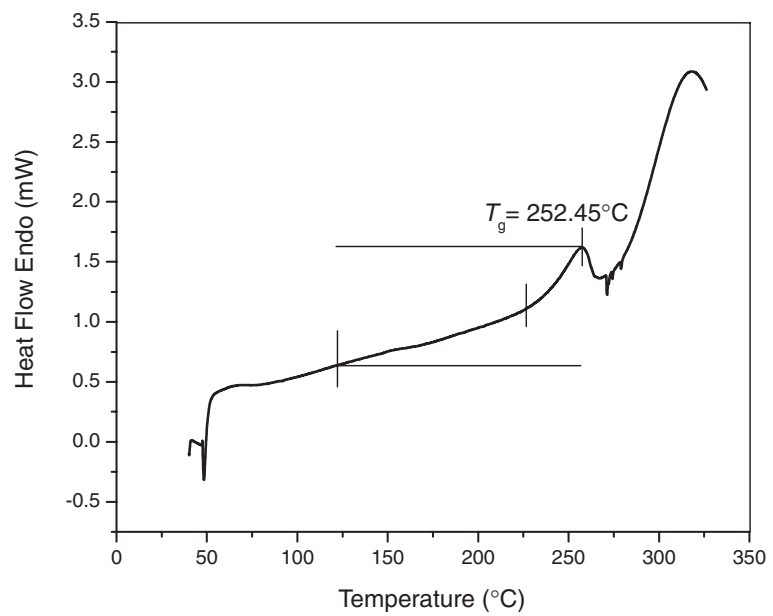

Figure 5. DSC thermogram of chiral polymer.

polymer was carried out at a heating rate of $10{ }^{\circ} \mathrm{C} \mathrm{min}^{-1}$ in a nitrogen atmosphere and the figure is shown in Figure 5. Melting endothermic peak was obtained at $125-270^{\circ} \mathrm{C}$ for this chiral polymer. The melting point and the heat capacity of the polymer was determined from the endothermic peak and found as $253{ }^{\circ} \mathrm{C}$ and $0.954 \mathrm{~J} / \mathrm{g}^{*}{ }^{\circ} \mathrm{C}$ respectively. The chiral polymer exhibits a single peak indicating the formation of random copolymer.

\section{Adsorption Isotherm}

Assuming one-to-one complexation of chiral moiety and enantiomers, as reported in our previous communication, ${ }^{3}$ complexation can be described analogously to Langmuir isotherm for localized nonlinear monolayer adsorption. Accordingly, single complexation can be described as

$$
q_{\mathrm{nR}}=\frac{X_{\mathrm{mR}} K_{\mathrm{R}} C_{\mathrm{eR}}}{1+K_{\mathrm{R}} C_{\mathrm{eR}}}
$$

and

$$
q_{\mathrm{nS}}=\frac{X_{\mathrm{mS}} K_{\mathrm{S}} C_{\mathrm{eS}}}{1+K_{\mathrm{S}} C_{\mathrm{eS}}}
$$


Table III. Parameter values for the adsorption isotherm of R- and S-isomer of different racemate on chiral polymeric membrane

\begin{tabular}{|c|c|c|c|c|c|c|}
\hline \multicolumn{7}{|c|}{ Langmuir model } \\
\hline \multirow[b]{3}{*}{ Racemate } & \multirow{2}{*}{\multicolumn{3}{|c|}{$\begin{array}{c}\text { S-isomer } \\
q_{\mathrm{nS}}=\frac{X_{\mathrm{mS}} K_{\mathrm{S}} C_{\mathrm{eS}}}{1+K_{\mathrm{S}} C_{\mathrm{eS}}}\end{array}$}} & \multirow{2}{*}{\multicolumn{3}{|c|}{$\begin{array}{c}\text { R-isomer } \\
q_{\mathrm{nR}}=\frac{X_{\mathrm{mR}} K_{\mathrm{R}} C_{\mathrm{eR}}}{1+K_{\mathrm{R}} C_{\mathrm{eR}}}\end{array}$}} \\
\hline & & & & & & \\
\hline & $\begin{array}{c}K_{\mathrm{S}} \\
\left(\mathrm{mM}^{-1}\right)\end{array}$ & $\begin{array}{c}X_{\mathrm{mS}} \\
(\mathrm{mM})\end{array}$ & $R^{2}$ & $\begin{array}{c}K_{\mathrm{R}} \\
\left(\mathrm{mM}^{-1}\right)\end{array}$ & $\begin{array}{c}X_{\mathrm{mR}} \\
(\mathrm{mM})\end{array}$ & $R^{2}$ \\
\hline $\begin{array}{l}\text { Propranolol } \\
\text { hydrochloride }\end{array}$ & 3.2700 & 5.4531 & 0.9952 & 0.0476 & 176.7801 & 0.9059 \\
\hline Atenolol & 5.0094 & 5.2462 & 0.9164 & 0.0710 & 60.9045 & 0.9075 \\
\hline Salbutamol & 5.9875 & 5.2030 & 0.9427 & 0.1855 & 18.9100 & 0.9651 \\
\hline Captopril & 16.5952 & 3.7329 & 0.9615 & 3.9105 & 16.2155 & 0.9343 \\
\hline
\end{tabular}

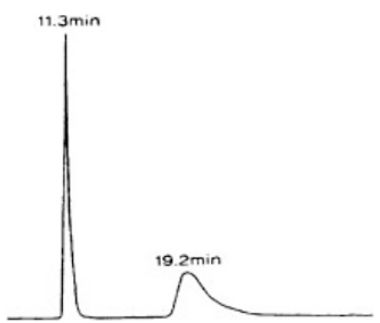

(R)

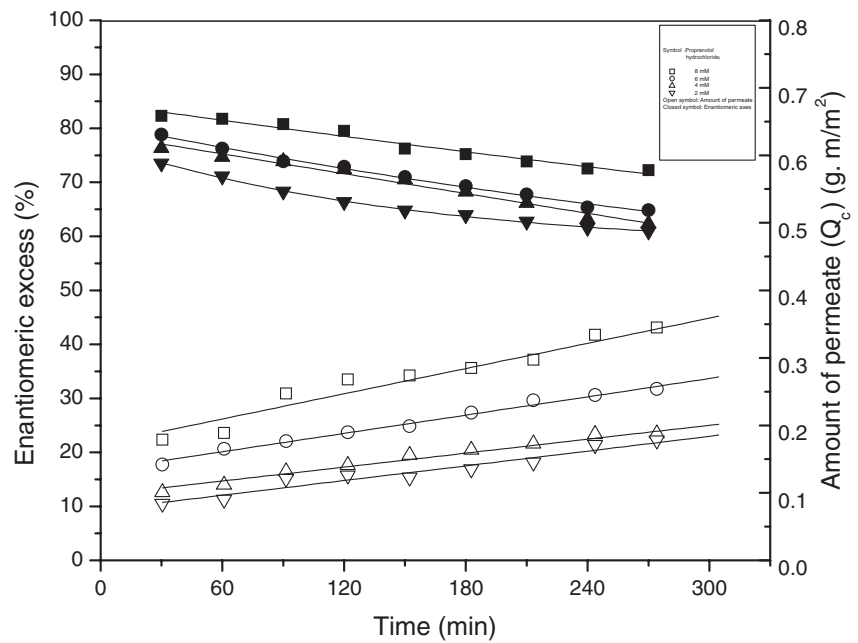

Figure 6. Effect of feed concentration (Propranolol hydrochloride) on amount of permeate and Enantiomeric excess.

where $K\left(\mathrm{mM}^{-1}\right)$ is the Langmuir affinity constant, $C_{\mathrm{e}}$ and $q_{\mathrm{n}}$ $(\mathrm{mM})$ are the equilibrium concentration of bulk and bound enantiomers respectively. The indices $R$ and $S$ refer to the $R$ and $S$ enantiomers respectively. The Langmuir saturation constant $X_{\mathrm{m}}(\mathrm{mM})$ is the maximum attainable concentration of bound enantiomer.

Table III shows the value of the isotherm parameters estimated by non-linear regression analysis. The value provides the most satisfactory representation of the experimental data almost at all experimental sets which confirm the enantioselective adsorption of the racemate on the chiral membrane.

\section{Enantioselective Permeation}

Effect of Feed Concentration. Figure 6 to Figure 9 shows the effect of feed concentration on the optical resolution of racemic compounds wherin the HPLC chromatograms are also shown. As the feed concentration increases from $2 \mathrm{mM}$ to $8 \mathrm{mM}$, the amount of the racemate penetrated through the membranes increases drastically, while the enantioselectivity of the membranes decreases equally. The results obtained are same as in case of resolution of tryptophan and tyrosine. ${ }^{16}$ This result suggest that by the increase in the concentration of the feed solution, too much of both the kinds of isomers ( $\mathrm{R}$ and $\mathrm{S}$ ) were absorbed into the chiral membrane, and then the absorbed $\mathrm{S}$-isomer diffuses with slower diffusion rate inferred the easy diffusion of the R-isomers. Consequently, the amounts of both $\mathrm{R}$ - and S-isomers penetrated through the membrane increases per unit time, but the difference in the diffusion rates of $\mathrm{R}$ - and $\mathrm{S}$-isomers became less, resulting in the low enantioselectivity. Effect of Operating Pressure. The effect of operating pressure on the resolution of racemic compound are shown in Figures 10-13. The conditions applied for studying this phenomena is same as used for the effect of concentration. From the figure it is seen that with increasing pressure, the amount of racemate penetrated increases with higher degree of S-isomer and go on decreasing the enantioselectivity of the membrane, the result is same as reported by Kim et al. ${ }^{16}$ This kind of phenomena most commonly encountered in the membrane separation process. The solution-diffusion model has usually determine the selectivity of a dense membrane for both sorption and diffusion selectivity. Generally the diffusion selectivity decreases with increasing driving force for the movement of solutes, eventually decreasing over all permselectivity. With increasing pressure, the over all enantioselectivity decreases whereas the permeation of S-isomer increases dominantly.

Mechanism of Enantioselective Permeation. The mechanism of enantioselective permeation may be analyzed by studying adsorption of the racemic compound on the chiral polymeric membrane. From the adsorption study it was found that S- 


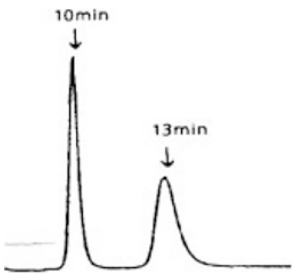

$(R)$

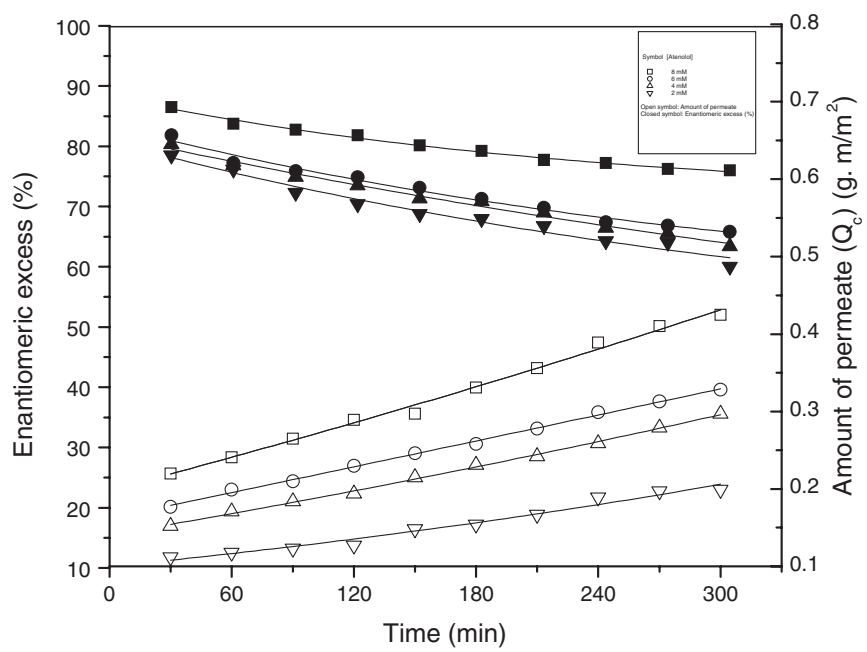

Figure 7. Effect of feed concentration (Atenolol) on amount of permeate and enantiomeric excess.

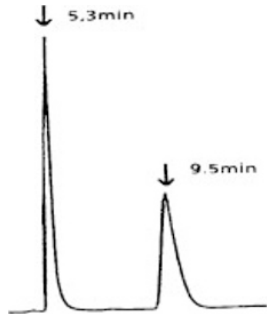

$(R)$

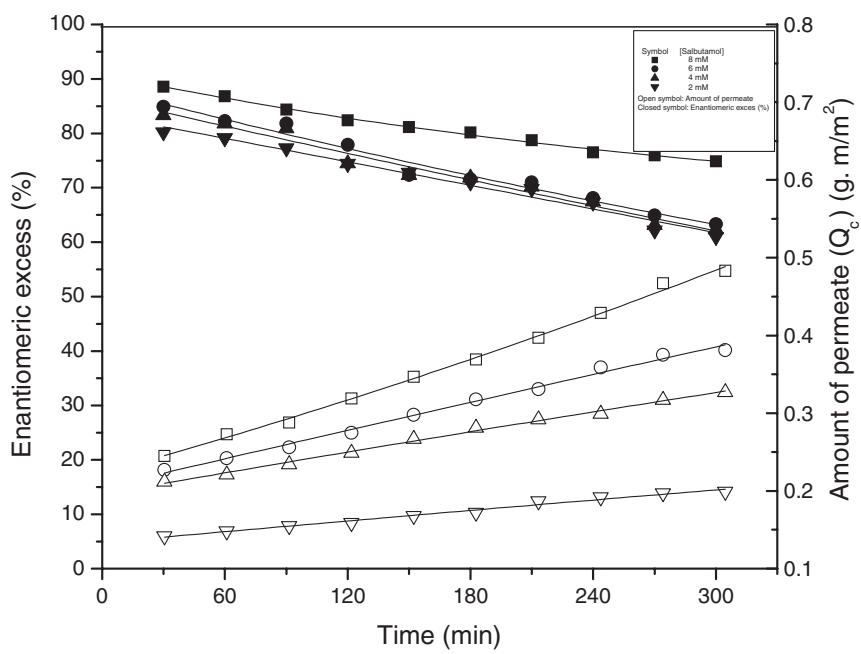

Figure 8. Effect of feed concentration (Salbutamol) on amount of permeate and enantiomeric excess.

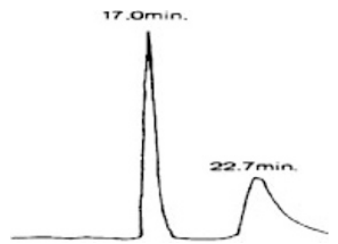

$(R)$

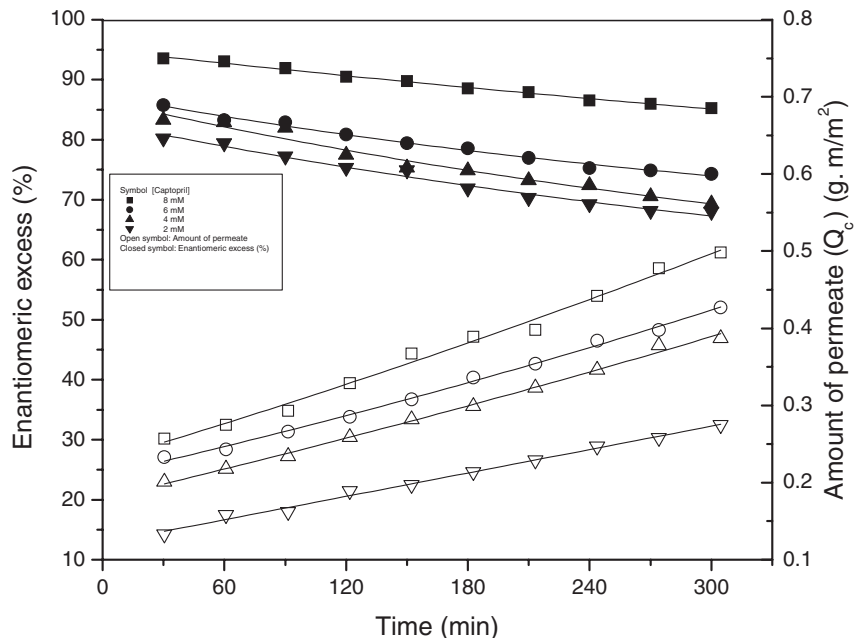

Figure 9. Effect of feed concentration (Captopril) on amount of permeate and enantiomeric excess. 


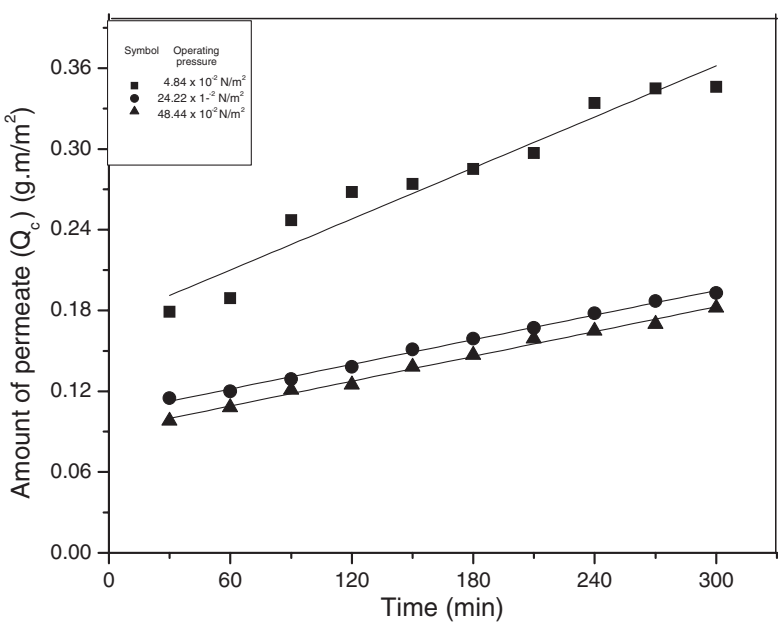

Figure 10. Effect of operating pressure on permeation rate of propranolol hydrochloride.

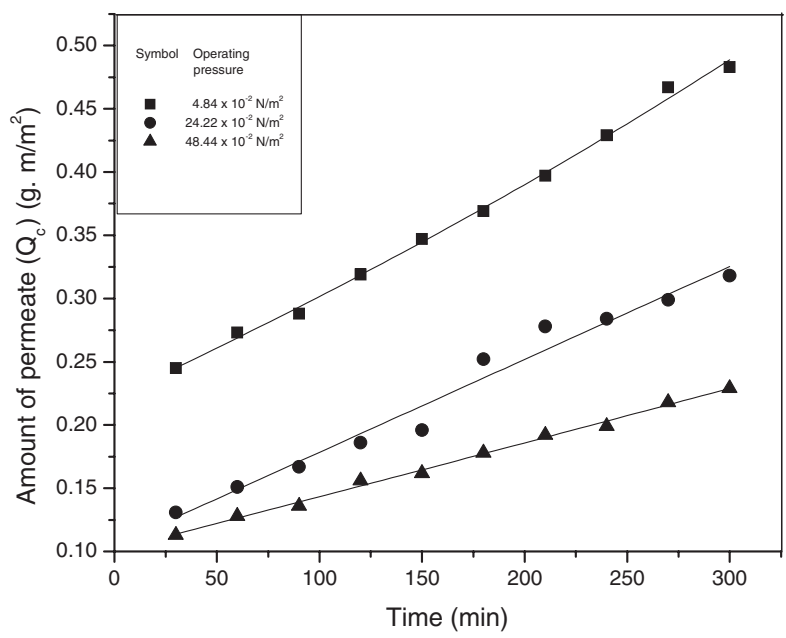

Figure 12. Effect of operating pressure on permeation rate of salbutamol.

isomers of all the racemates were enantioselectively adsorbed and R-isomers were permeated through the membrane. The permeation of $\mathrm{S}$-isomers were suppressed by the $\mathrm{S}$-isomers of the chiral polymers present in the membrane due to self association behaviour. ${ }^{17}$ The permeation performance of the membrane is not dependent on the $\alpha$-helix structure of the chiral compound but it depends on the asymmetric carbon present in the polymer. ${ }^{3}$ Thus the self association behaviour of the adsorbed isomer on the membrane is reasonable.

Analysis by Solution-Diffusion Mechanism. The enantioselective permeation of racemic compound can be analyse by solution diffusion mechanism, i.e., $\mathrm{P}_{\mathrm{c}}=\mathrm{DS}$, where $\mathrm{P}_{\mathrm{c}}$ is the permeation co-efficient, $\mathrm{D}$ is the diffusion co-efficient and $\mathrm{S}$ is the solution co-efficient. Here solution co-efficient, $\mathrm{S}=$ $\mathrm{S}_{\mathrm{R}} / \mathrm{S}_{\mathrm{S}} \approx 1$ and $\mathrm{D}=\mathrm{D}_{\mathrm{R}} / \mathrm{D}_{\mathrm{S}}, \mathrm{P}_{\mathrm{c}}=\mathrm{P}_{\mathrm{cR}} / \mathrm{P}_{\mathrm{cS}}$. Table IV summarizes the results of the analysis.

It is seen that the values of $\mathrm{P}_{\mathrm{cR}} / \mathrm{P}_{\mathrm{cS}}$ were governed by the $D_{R} / D_{S}$ values and hence enantioselectivity occurred by diffusion process but not in the solution process. In other

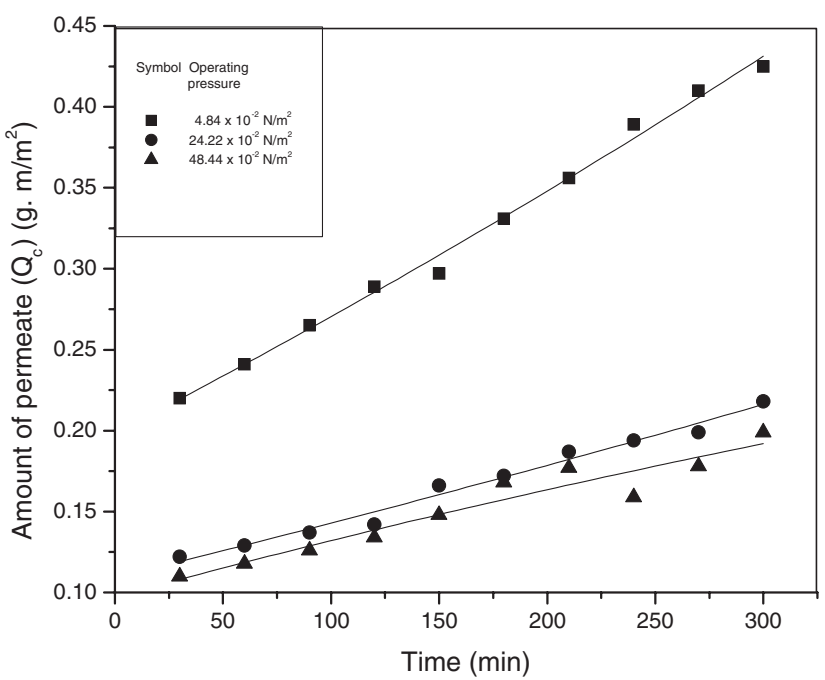

Figure 11. Effect of operating pressure on permeation rate of atenolol.

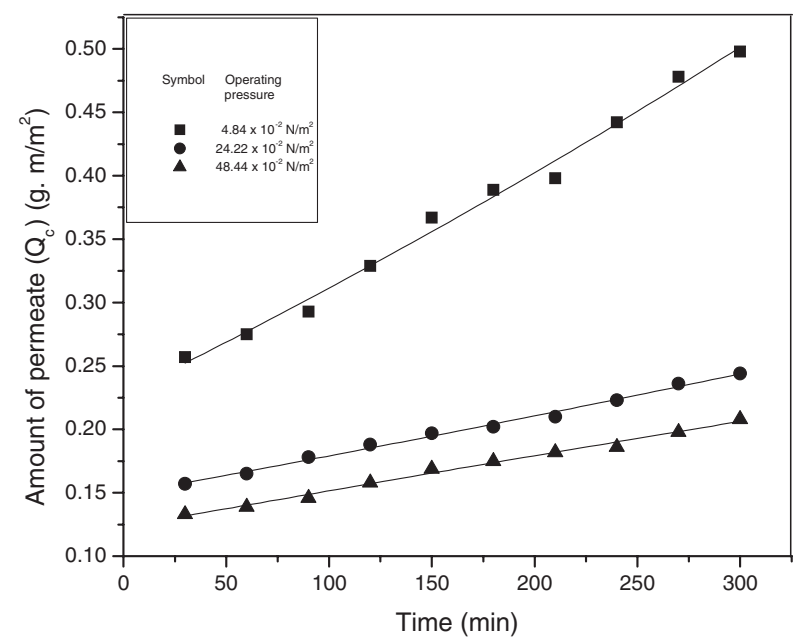

Figure 13. Effect of operating pressure on permeation rate of captopril.

Table IV. Analysis for enantioselective permeation through chiral polymeric membrane by the solution-diffusion mechanism

\begin{tabular}{lccc}
\hline Racemate & $\mathbf{P}_{\mathbf{R}} / \mathbf{P}_{\mathbf{S}}$ & $\mathbf{D}_{\mathbf{R}} / \mathbf{D}_{\mathbf{S}}$ & $\mathbf{S}_{\mathbf{R}} / \mathbf{S}_{\mathbf{S}}$ \\
\hline Propranolol & 2.6 & 2.2 & 1.6 \\
hydrochloride & 3.1 & 3.4 & 0.7 \\
Atenolol & 3.3 & 2.7 & 1.2 \\
Salbutamol & 3.8 & 3.6 & 1.1 \\
Captopril & &
\end{tabular}

words, the enantioselective permeation was achieved not by selective dissolution at the membrane surface but by the selective diffusion through the chiral center of the chiral polymeric membrane. This behaviour is due to enantioselective adsorption of the enantiomer. The mechanism is same for enantioselective permeation of some amino acids and alcohols through optically active poly\{1-[dimethyl(10-pinanyl)silyl]-1propyne\} membrane. ${ }^{8}$ 
It is also seen that the $P_{c}$ value was governed by the $S$ values but not the $\mathrm{D}$ values. The racemates with higher affinity for the chiral polymer permeated more rapidly. This can be explained from the hydrophobic fragmental constant as reported by Aoki et $a .^{8}$

\section{CONCLUSION}

Chiral polymeric membrane prepared from chiral polymer and polysulfone are used for racemic resolution of four compounds viz. propranolol hydrochloride, atenolol, salbutamol and captopril by pressure driven process. The chiral polymeric membrane has better enantioselectivity through increased interactions between the functional groups of the chiral environment of the membrane and the penetrating solutes. The other factors such as increase in operating pressure, increase in concentration of the feed solution and decrease in the size of the solute can reduce the intermolecular interaction between the membrane and solute and act against the enantioselectivity. The permeation performance of the membrane is not dependent on the $\alpha$-halix structure of the chiral compound but it depends on the asymmetric carbon present in the polymer. Thus the self association behaviour of the absorbed isomer on the membrane is reasonable. That can reduce the intermolecular interaction between the membrane and solutes such as increase in operating pressure, an increase in the concentration of the feed solution and smaller solutes. These factors can decrease the intermolecular interaction between the membrane and solutes and act against the enantioselectivity. The enantioselective permeation was achieved not by selective diffusion through the chiral center of the chiral polymeric membrane. This behaviour is due to enantiomeric adsorption of the enantiomer. The isomer with higher affinity for the chiral polymer permeated more rapidly.

\section{Nomenclature}

$q$ amount of $\mathrm{R}$ or $\mathrm{S}$-isomer adsorbed per gm of chiral polymer $\left(\mathrm{mmol} \mathrm{g}^{-1}\right)$

$\Delta C$ change in solute concentration $(\mathrm{mM})$

$V_{1}$ solution volume (L)

$W_{1}$ weight of adsorbent (g)

Q quantity of the solute permeated for a given time $(\mathrm{g})$

$t$ permeation time $(\mathrm{h})$
A membrane area $\left(\mathrm{m}^{2}\right)$

$\mathrm{A}_{\mathrm{R}}$ peak area of $\mathrm{R}$-isomer

$\mathrm{A}_{\mathrm{S}}$ peak area of $\mathrm{S}$-isomer

$\mathrm{J}$ flux of the membrane $\left(\mathrm{g} \mathrm{m} / \mathrm{m}^{2} \mathrm{~h}\right)$

$K$ Langmuir affinity constant $\left(\mathrm{mM}^{-1}\right)$

$C_{\mathrm{e}}$ equilibrium concentration of bulk enantiomer (mM)

$q_{\mathrm{n}}$ equilibrium concentration of bound enantiomer (mM)

$X_{\mathrm{m}}$ Langmuir saturation constant (mM)

$\mathrm{P}_{\mathrm{c}}$ Permeation co-efficient

D Diffusion co-efficient

S Solution co-efficient

Acknowledgment. Financial support by Grant-in-Aid for Scientific Research from Department of Science and Technology, New Delhi is gratefully acknowledged.

Received: June 13, 2009

Accepted: August 15, 2009

Published: October 2, 2009

\section{REFERENCES}

1. K. Komura, N. Nishitani, and S. Itsuno, Polym. J., 31, 1045 (1999).

2. S. Itsuno and K. Komura, Tetrahedron, 58, 8237 (2002).

3. S. Hazarika, J. Membr. Sci., 310, 174 (2008).

4. T. Aoki, S. Tomizawa, and E. Oikawa, J. Membr. Sci., 99, 117 (1995).

5. T. Aoki, A. Maruyama, K. Shinohara, and E. Oikawa, Polym. J., 27, 547 (1995).

6. K. Shinohara, T. Aoki, T. Kaneko, and E. Oikawa, Polymer, 42, 351 (2001).

7. K. Shinohara, T. Aoki, and E. Oikawa, Polymer, 36, 2403 (1995).

8. T. Aoki, K. Shinohara, T. Kaneko, and E. Oikawa, Macromolecules, 29, 4192 (1996).

9. A. Maruyama, N. Adachi, T. Takatsuki, M. Torii, K. Sanui, and N. Ogata, Macromolecules, 23, 2748 (1990).

10. J. Randon, F. Garnier, J. L. Rocca, and B. Maïterrena, J. Membr. Sci., 175, 111 (2000).

11. T. Nakagawa, Y. Toyokawa, M. Abe, and A. Higuchi, Macromol. Symp., 84, 209 (1994).

12. T. Aoki, M. Ohshima, K. Shinohara, T. Kaneko, and E. Oikawa, Polymer, 38, 235 (1997).

13. J. Marchese and C. L. Pagliero, Gas Sep. Purif., 5, 215 (1991).

14. M. Teraguchi, K. Mottate, S. Y. Kim, T. Aoki, T. Kaneko, S. Hadano, and T. Masuda, Macromolecules, 38, 6367 (2005).

15. M. Teraguchi and T. Masuda, Macromolecules, 35, 1149 (2002).

16. J. H. Kim, J. H. Kim, J. Jegal, and K. H. Lee, J. Membr. Sci., 213, 273 (2003).

17. S. Hazarika, N. N. Dutta, and P. G. Rao, J. Appl. Membr. Sci. Technol., 2, 13 (2006). 